\title{
Don't imitate
}

\author{
Wait for the real thing.
}

\section{Gilles Amon}

The obvious one to choose, but the most difficult one to conceptualize. The last bottle of the evening, of course, has to be her. The diva. The grande dame.

It will seem unreal to get in touch with the Palmer '07 one more time - maybe for the last time. Distant memories of her playful youth will surface; and of the painfully long time it took her to mature, or rather, to transform. Only when she was well into her third decade did she start truly to intrigue us, at a point when we had almost stopped believing that there was something extraordinary in this wine. And extraordinary she is.

Of course, we could have paid more attention to certain details. A few did. But we opened the young bottles far too carelessly, too often and too soon. Had we only had the slightest idea of what a splendid future the 2007 was to experience, we wouldn't have put a premature end to the lives of so many bottles, depriving each one of the peaks to come.

But we did - like most of us so-called real wine aficionados. The most painful thing about having emptied so many bottles decades ago - rather than celebrating them now, when the wine is at the top of its game, and has left standing everything that was ever put in a bottle - the most painful thing is that, had we shown more foresight, it would not be my last bottle of beloved Palmer '07 that we will open tonight.

The biggest worry, of course, is - as with all bottles that are not glued - the cork. But I trust it will be fine. The bottle got a new cork in 2037, au château. How on Earth they managed to find natural corks 12 years after the European Union banned them, I have no idea. It seemed, back then, fairly early to be replacing the cork, but it was really the last opportunity to do so.

Not that much can be said against gluing the bottles (thankfully, there still are bottles around that need to be properly sealed). Far beyond the environmental aspect, the glue is just perfect nowadays. Many don't even own corkscrews any more. (I always held on to mine, like scientists who will never ditch their pencils.) The glue never, ever leaks. Never. Easily ripped off — and easily resealed, if you like that kind of thing.

After all, resealing is still better than pouring away your 2003 d'Yquem or 1945 Mouton, once you've had enough for the evening. This has become such a bad

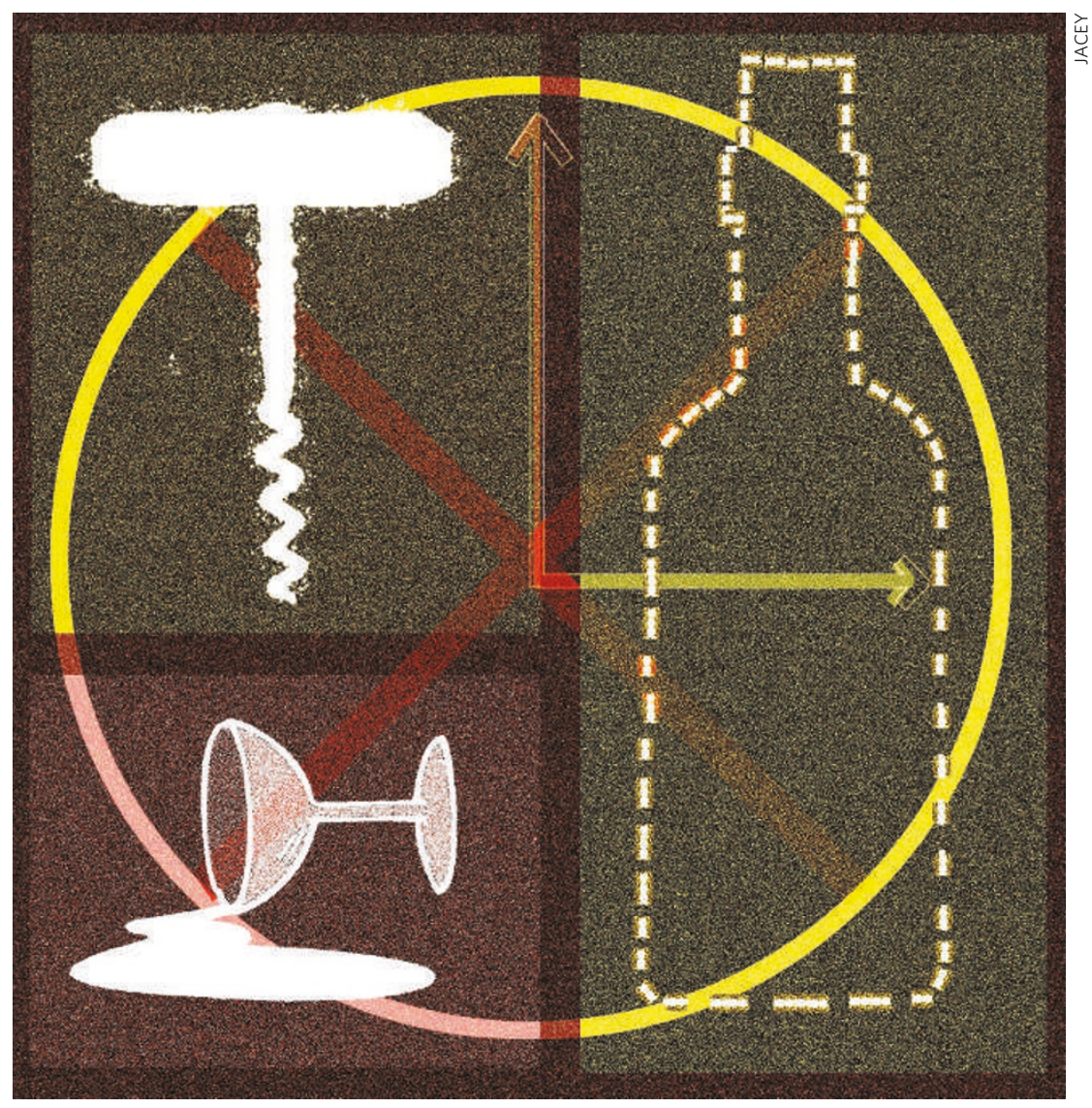

habit. But there are hundreds of other reasons to dislike imitations. They cannot be distinguished from the originals, of course. Who could forget that, 20 years ago, Gabriel Robertson - the elder — was unable to identify a single 'fake' in a series of 24 wines, which included some of his personal favourites? A shock.

Back then 'test-tube wines' were still produced under the Dior name, I think, before the branch was taken out of the group a few years later to form Vinor. No one can deny that it was the heavy involvement of the perfume industry that drove the early, purely scientific attempts at 'copying' famous vintages - for archival reasons, they said - away from their initial innocence, and towards a monstrous industry.

It wasn't long before everyone owned every vintage of Pétrus ever produced. A period of unspeakable snobbism began: "I don't ruin my burger with a 99-point wine." Give me a break. Even today, I find it devastating that everybody ran with the idea - and most still do. At least that cruelty of 'instant wines' never got off the ground. But nonetheless, countless wineries were faced with ruin, most of them small, independent concerns; but also some big names. Fortunately, the majority of the Grands Crus survived; at least, those of the 2021 reclassification.

Oh yes, you can still find them, the pearls, but you have to sniff them out. And new stars have appeared, but only a handful, produced by enthusiasts who, audaciously, set out to celebrate wines in their entirety with the same intensity as us. Lucky us, who, unperturbed, kept on searching for real wines, 'vinified wines', as they call them these days.

While others stick their noses in 'Best of Wine' collections from the corner shop, we are the ones who can see great vintages develop, as they become, well, ready. The 2029s, the 2039s and, above all, the 2007s. Only we witnessed history unfolding, snapshot by snapshot. Often you don't have much of an idea what will have happened since the last time you looked. Some of the best stories are still being written. And much is still to come, many surprises, I dare say.

Well, enough talking. Let us celebrate the diva.

Gilles Amon lives in London and enjoys wines. 